\title{
Estratégias de seleção para germinação de sementes de cenoura em alta temperatura
}

\author{
Giovani Olegário da Silva ${ }^{1}$, Jairo Vidal Vieira², Warley Marcos Nascimento ${ }^{3}$
}

\begin{abstract}
RESUMO
Os cultivares do grupo Brasília apresentam boa adaptação às condições de cultivo durante o verão no Brasil. Entretanto, há necessidade de se fazer seleção para aumentar o potencial de germinação em temperatura elevada, propiciando economia de sementes e estandes mais uniformes, principalmente em regiões quentes do País. O objetivo deste trabalho foi definir estratégias para maximizar os ganhos na qualidade de sementes de cenoura utilizando-se famílias de meios-irmãos de população derivada do cultivar Brasília, avaliado quanto ao vigor e à germinação a 20 e 35 ${ }^{\circ} \mathrm{C}$. Foram avaliadas sementes de 70 famílias de meios-irmãos de cenoura, utilizando-se delineamento em blocos casualizados, com quatro repetições de 50 sementes de cada família. Os dados obtidos foram submetidos a análises de variância, e estimadas a herdabilidade, a correlação entre os caracteres e os ganhos diretos com a seleção e por meio de índices de seleção. Vigor e germinação mostraram eficiência para diferenciar as famílias avaliadas a 20 e $35^{\circ} \mathrm{C}$. Os índices de seleção avaliados tiveram desempenho idêntico nas duas temperaturas testadas; sendo assim, a seleção pode ser feita com a utilização de qualquer um dos índices. A temperatura de $35^{\circ} \mathrm{C}$ mostrou elevado ganho por seleção em relação a $20^{\circ} \mathrm{C}$.
\end{abstract}

Palavras-chave: Daucus carota L., termoinibição, estabelecimento de plântulas.

\section{ABSTRACT}

\section{Selection strategies for carrot seed germination at high temperature}

Carrot cultivars of the Brasília group have good adaptation to cultivation in summer conditions in Brazil. However, there is the need for selection to increase the germination potential at high temperature in order to reduce seed costs and to obtain more uniform stands, mainly in hot areas of the country. The objective of this work was to define the best strategy to maximize gains in quality of carrot seeds using half-sib families derived from a population of the cultivar Brasília assessed for vigor and germination at 20 and $35^{\circ} \mathrm{C}$. Seeds of 70 half-sib families of carrot were evaluated using a randomized block design with 4 replicates of 50 seeds for each family. Data were examined by analysis of variance, and the parameters heritability and correlation between the traits and the direct genetic gains by selection and by selection indexes were estimated. It was found that vigor and germination were efficient to distinguish the families evaluated at the temperatures 20 and $35^{\circ} \mathrm{C}$. The evaluated selection indexes showed identical performance at the two temperatures, thus, selection can be performed by using any of the indexes. The temperature at $35^{\circ} \mathrm{C}$ provided higher gain than at $20^{\circ} \mathrm{C}$.

Key words: Daucus carota L., thermo-inhibition, plantlet establishment.

Recebido para publicação em março de 2009 e aprovado em outubro de 2009

${ }^{1}$ Engenheiro-Agrônomo, Doutor. Empresa de Pesquisa Agropecuária Embrapa, Centro Nacional Pesquisa de Hortalíças, Caixa-Postal 218, 70352-970, Brasilia, Distrito Federal, Brasil. olegario@cnph.embrapa.br. Autor para correspondência.

${ }^{1}$ Engenheiro Agrônomo, Doutor. Empresa de Pesquisa Agropecuária Embrapa, Centro Nacional Pesquisa de Hortalíças, Caixa-Postal 218, 70352-970, Brasilia, Distrito Federal, Brasil. jairo@cnph.embrapa.br

${ }^{2}$ Engenheiro Agrônomo, Doutor. Empresa de Pesquisa Agropecuária Embrapa, Centro Nacional Pesquisa de Hortalíças, Caixa-Postal 218, 70352-970, Brasilia, Distrito Federal, Brasilwmn@cnph.embrapa.br 


\section{INTRODUÇÃO}

O desenvolvimento de cultivares de cenoura com tolerância ao calor e resistência às principais doenças da cultura tem propiciado aumento da área de cultivo em regiões de clima quente, principalmente no Nordeste e Centro-Oeste do Brasil.

Dentre os cultivares de cenoura já desenvolvidos para o verão, destacam-se os do grupo Brasília, incluindo ‘Alvorada’, ‘Brasilia’ e ‘Esplanada’. Estes cultivares apresentam desempenho superior em relação aos outros comercializados no País quanto à produtividade, resistência à queima das folhas e adaptação às condições de cultivo do Brasil durante o verão. Entretanto, quanto à capacidade de germinação em temperaturas elevadas (acima de 35 ${ }^{\circ} \mathrm{C}$ ), o desempenho desses cultivares, similarmente aos demais em uso no País, não tem revelado resultados satisfatórios (Pereira \& Nascimento, 2002; Pereira, 2005).

Esse fato, além de explicar parcialmente a menor germinação de sementes, especificamente do cultivar Brasília em algumas regiões, como na microrregião de Irecê (BA) nos meses mais quentes do ano, com consequente redução de estande e produtividade nos sistemas de produção em uso na região, evidencia a necessidade de desenvolvimento de novos cultivares com maior capacidade de germinação e estabelecimento de plantas em condições de temperaturas elevadas, como alternativa para garantir competitividade da produção de cenoura das regiões Nordeste e Centro Oeste (Pereira, 2005).

Para tal, o conhecimento a respeito da magnitude dos valores de herdabilidade para as características sob seleção é essencial, permitindo o estabelecimento de um conjunto de estratégias de seleção e métodos de melhoramento genético muito mais efetivos (Alves et al., 2004). A herdabilidade é uma medida do grau em que o fenótipo é influenciado geneticamente e, portanto, quanto ele pode ser modificado por seleção (Eberhart, 1970; Carvalho et al., 2001). O melhoramento pode ser ainda mais efetivo com a utilização de índices de seleção que possibilitam combinar as informações contidas na unidade experimental, de modo que seja possível a seleção com base em um conjunto de variáveis que reúna atributos de interesse econômico para o produtor e consumidor (Cruz \& Regazzi, 2001).

O objetivo deste trabalho foi definir a melhor estratégia para maximizar os ganhos na qualidade de sementes de cenoura, utilizando-se famílias de meios-irmãos de população derivada do cultivar Brasília, avaliadas para vigor e germinação a 20 e $35^{\circ} \mathrm{C}$ (condição adversa).

\section{MATERIAL E MÉTODOS}

Os experimentos foram implementados no Laboratório de Sementes da Embrapa Hortaliças, Distrito Federal, no ano de 2007. Foram avaliadas 70 famílias de meiosirmãos de cenoura de população obtidas por cinco ciclos de seleção recorrente para germinação em alta temperatura a partir de população derivada do cultivar Brasília, utilizando-se o delineamento em blocos casualizados, com quatro repetições e 50 sementes de cada família. As sementes foram colocadas em caixas plásticas de germinação, sobre duas folhas de papel mata-borrão umedecidas com 15 mL de solução fungicida (Iprodione + Tiram 3:1 4 g/1000 mL de água destilada) por caixa. Em seguida, elas foram colocadas para germinar em câmara do tipo “NKSystem”, sob luz artificial com fotoperíodo de 24 horas, regulada a 20 (ótima) e $35^{\circ} \mathrm{C}$ (adversa). Independentemente da temperatura de realização do ensaio, as sementes foram avaliadas aos sete dias após a semeadura (primeira contagem), o que corresponde à avaliação do vigor de sementes de cenoura (Bittencourt, 1991), e aos 14 dias (contagem final). Os resultados foram expressos em porcentagem média de sementes germinadas (protrusão da raiz primária).

Os dados foram submetidos à análise de homogeneidade de variância (teste de Bartllet) e de normalidade (Lilliefors). Os dados dos caracteres quantificados a 35 ${ }^{\circ} \mathrm{C}$ foram transformados por $\sqrt{x+0,50}$, para atender à pressuposição de normalidade de distribuição. Efetuouse análise de variância para cada temperatura. Posteriormente, realizou-se a análise conjunta dos dados utilizando-se o modelo $Y_{i j k}=m+B / A_{j k}+G_{i}+A_{j}+G_{A i j}+E_{i j k}$, em que: $\mathrm{Y}_{\mathrm{ijk}}=$ efeito do i-ésimo genótipo no j-ésimo ambiente e k-ésima repetição, $\mathrm{m}$ = média de família, $\mathrm{B} / \mathrm{A}_{\mathrm{jk}}=$ efeito do j-ésimo bloco no k-ésimo ambiente, $\mathrm{G}_{\mathrm{i}}=$ efeito do iésimo genótipo, $\mathrm{A}_{\mathrm{j}}=$ efeito do j-ésimo ambiente, $\mathrm{GA}_{\mathrm{ij}}=$ efeito devido à interação entre o i-ésimo genótipo e jésimo ambiente e $\mathrm{E}_{\mathrm{ijk}}=$ resíduo. Para cada temperatura, foram estimadas ainda a herdabilidade no sentido amplo, pelo quadrado médio (Cruz \& Regazzi, 2001); a correlação genotípica entre os caracteres; os ganhos com a seleção em que foram escolhidas as melhores famílias, adotando-se uma pressão de seleção de $20 \%$, selecionando-se 14 famílias, e foram estimados os ganhos diretos por seleção, sendo GS = DS.h², em que DS = diferencial de seleção ou diferença entre a média dos selecionados subtraída da média da população base; e $\mathrm{h}^{2}=$ herdabilidade com base na média. Esses ganhos diretos em cada caráter serviram como referencial para a avaliação do desempenho de índices de seleção aplicados (Santos \& Araújo, 2001).

Os índices de seleção utilizados foram: clássico, proposto por Smith (1936) e Hazel (1943); base de Willians (1962), com base nos ganhos desejados de Pesek \& Baker (1969); e livre de pesos e de parâmetros de Elston (1963), segundo Cruz \& Regazzi (2001). O peso dos caracteres foi igual ao desvio-padrão genético para todos os índices, 
exceto o de livre de peso e parâmetros de Elston (1963), em que os valores mínimos foram iguais à média para cada caráter, utilizando-se o aplicativo computacional Genes (Cruz, 1997).

\section{RESULTADOS E DISCUSSÃO}

Para ambos os caracteres (vigor e germinação), nas duas temperaturas houve homogeneidade das variâncias residuais. Da mesma forma, atenderam à pressuposição de normalidade de distribuição após transformação dos dados obtidos a $35^{\circ} \mathrm{C}$.

Verificou-se pela análise de variância conjunta dos dados que para ambos os caracteres (vigor e germinação) a interação família x temperatura foi significativa; dessa forma, as temperaturas utilizadas não influenciaram da mesma forma a expressão dos caracteres. Em face disso, assumiu-se que as inferências sobre os diferentes parâmetros devem ser efetuadas para cada temperatura (Tabela 1).

De acordo com a análise de variância para $20^{\circ} \mathrm{C}$ (Tabela 2), ambos os caracteres foram significativos em diferenciar as famílias avaliadas. Os coeficientes de variação foram reduzidos, indicando adequada precisão experimental, e os valores de herdabilidade foram medianos, sendo superiores para a germinação de sementes. Da mesma forma, a relação entre os coeficientes de variação genético e ambiental, em que estimativas acima de 1,00 determinam elevado ganho genético, foi de 0,79 e 1,03 (Tabela 2), indicando que existe a possibilidade de obtenção de ganhos com a seleção, principalmente para o caráter germinação de sementes. No entanto, a temperatura de $20^{\circ} \mathrm{C}$, que é a recomendada para testes de germinação de cenoura (Brasil, 1992), é inferior às temperaturas do solo comumente observadas na semeadura de verão nas condições de clima da maioria das regiões brasileiras.
Em $35{ }^{\circ} \mathrm{C}$ os coeficientes de variação foram elevados para ambos os caracteres, indicando reduzida precisão experimental e consequente confiabilidade dos resultados (Tabela 2). Apesar disso, verificou-se diferença significativa entre famílias para os caracteres avaliados. Os valores de herdabilidade foram menores que a $20^{\circ} \mathrm{C}$, bem como a relação entre o coeficiente genético de variação e o ambiental, indicando que o ambiente influenciou mais na expressão dos caracteres naquela temperatura.

Os valores médios de germinação e vigor das sementes também foram reduzidos na temperatura mais alta, tendo o vigor reduzido de 90,73 para 2,51\%, enquanto a germinação de 93,96 para $3,23 \%$ em 20 e $35^{\circ} \mathrm{C}$, respectivamente (Tabela 2). Em $20^{\circ} \mathrm{C}$ o menor vigor foi de $74,50 \%$ e o valor máximo de $99 \%$, enquanto a menor germinação teve porcentagem de $80 \%$ e a maior $99 \%$ (Tabela 3). Em $35^{\circ} \mathrm{C}$, obteve-se o valor de $0 \%$ de vigor, com maior valor de $22,50 \%$. Na germinação final, observou-se o valor de $0 \%$, sendo a maior germinação de sementes de apenas 38\% (Tabela 4). Pereira (2005) verificou que a $35^{\circ} \mathrm{C}$ poucas progênies de meios-irmãos derivadas de Brasília possuem germinação superior a $60 \%$; observou ainda que a $35{ }^{\circ} \mathrm{C}$ cerca de $27 \%$ das famílias avaliadas não tiveram nenhuma semente germinada. Resultados semelhantes foram verificados por Carneiro \& Guedes (1992), em que sementes do cultivar Brasília germinaram $91 \%$ a $25^{\circ} \mathrm{C}$ e apenas $47 \%$ a $35{ }^{\circ} \mathrm{C}$, e por Pereira (2005), em que a $35^{\circ} \mathrm{C}$ poucas famílias de uma população derivada do grupo Brasília tiveram suas sementes germinando acima de $60 \%$.

Os ganhos estimados para vigor e germinação a $20^{\circ} \mathrm{C}$ foram de 4,63 e 3,30, respectivamente (Tabelas 3 e 4), enquanto os ganhos com a seleção por todos os índices testados foram muito semelhantes. Dessa forma, a seleção combinada poderia ser feita com a utilização de qualquer

Tabela 1. Resumo da análise de variância conjunta e estimativa dos valores da herdabilidade $\left(\mathrm{H}^{2}\right)$ e da relação coeficiente de variação genética sobre coeficiente de variação ambiental (CVg/Cve) para os caracteres vigor e germinação de sementes de cenoura, utiizandose 70 famílias de meios-irmãos de uma população derivada do cultivar Brasília avaliadas em condições de laboratório em temperaturas de 20 e $35^{\circ} \mathrm{C}$.

\begin{tabular}{lccc}
\hline \multirow{2}{*}{ Fonte de variação } & GL & \multicolumn{2}{c}{ Quadrado médio } \\
\cline { 3 - 4 } & & 87,78 & Germinação \\
\hline Blocos/ambiente & 69 & $73,88^{*}$ & 29,28 \\
Famílias (F) & 1 & $1089644,04^{*}$ & $30,74^{*}$ \\
Temperatura (T) & 69 & $69,42^{*}$ & $1152457,90^{*}$ \\
F x T & 414 & 6,85 & $35,33^{*}$ \\
Resíduo & - & 9,74 & 7,17 \\
CVe & - & 72,08 & 5,39 \\
H $^{2}$ & - & 0,57 & 77,72 \\
CVg/CVe & - & 46,62 & 0,66 \\
Média & & & 48,59 \\
\hline
\end{tabular}

*Significativo a 5\% de probabilidade de erro pelo teste $\mathrm{F}$.

Rev. Ceres, Viçosa, v. 57, n.1, p. 060-065, jan/fev, 2010 
índice testado. Não só os ganhos foram semelhantes, mas também a porcentagem média das famílias que foram selecionadas por ambos os critérios (seleção direta para vigor e para germinação) e índices de seleção (Tabela 3).
A correlação genotípica entre germinação e vigor a 20 ${ }^{\circ} \mathrm{C}$ foi alta $(0,82)$, o que se confirmou pela porcentagem de famílias que foram selecionadas para ambos os caracteres na seleção direta (Tabela 3).

Tabela 2. Resumo da análise de variância e estimativa dos valores de herdabilidade $\left(\mathrm{H}^{2}\right)$ e da relação coeficiente de variação genética sobre coeficiente de variação ambiental (CVg/Cve) para os caracteres vigor e germinação de sementes de cenoura, utiizando-se 70 famílias de meios-irmãos de população derivada do cultivar Brasília avaliadas em condições de laboratório em temperaturas de 20 e $35^{\circ} \mathrm{C}$.

\begin{tabular}{|c|c|c|c|}
\hline \multirow{2}{*}{ Fonte de variação } & \multirow{2}{*}{ GL } & \multicolumn{2}{|c|}{ Quadrado médio } \\
\hline & & Vigor & Germinação \\
\hline \multicolumn{4}{|c|}{ Temperatura $20^{\circ} \mathrm{C}$} \\
\hline Bloco & 3 & 161,42 & 41,69 \\
\hline Famílias (F) & 69 & $139,12^{*}$ & $60,11^{*}$ \\
\hline Resíduo & 207 & 41,43 & 11,83 \\
\hline $\mathrm{CVe}$ & - & 6,94 & 3,59 \\
\hline $\mathrm{H}^{2}$ & - & 71,47 & 81,04 \\
\hline $\mathrm{CVg} / \mathrm{CVe}$ & - & 0,79 & 1,03 \\
\hline Média & - & 90,73 & 93,96 \\
\hline \multicolumn{4}{|c|}{ Temperatura $35^{\circ} \mathrm{C}$} \\
\hline Bloco & 3 & 14,14 & 16,88 \\
\hline Famílias (F) & 69 & $4,18^{*}$ & $5.96 *$ \\
\hline Resíduo & 207 & 1,73 & 2,51 \\
\hline $\mathrm{CVe}$ & - & 49,53 & 47,06 \\
\hline $\mathrm{H}^{2}$ & - & 62,89 & 61,31 \\
\hline $\mathrm{CVg} / \mathrm{CVe}$ & - & 0,65 & 0,63 \\
\hline Média & - & 2,51 & 3,23 \\
\hline Média não transformada & - & 5,80 & 10,38 \\
\hline
\end{tabular}

*Significativo a 5\% de probabilidade de erro pelo teste $\mathrm{F}$.

Tabela 3. Estimativas de ganho genético esperado em porcentagem em relação à média, identificação das famílias selecionadas por método de seleção empregado, de acordo com a seleção direta e baseado em índices de seleção, percentual de coincidência de famílias selecionadas pelos diferentes métodos, amplitude das médias para os caracteres vigor e germinação de sementes, avaliados em condições de laboratório a $20^{\circ} \mathrm{C}$ e correlação genética entre os caracteres.

\begin{tabular}{|c|c|c|c|}
\hline \multicolumn{2}{|l|}{ Métodos de seleção } & \multicolumn{2}{|r|}{ Germinação } \\
\hline \multirow[t]{2}{*}{ Seleção direta } & Famílias selecionadas & $\begin{array}{c}13,41,9,30,17,23,43,63 \\
1,2,21,35,37,44\end{array}$ & $\begin{array}{c}9,13,17,30,37,41,12,21 \\
29,35,2,43,52,63\end{array}$ \\
\hline & Ganho de seleção & 4,63 & 3,30 \\
\hline Smith (1936) e Hazel (1943) & $\begin{array}{c}\text { Famílias selecionadas } \\
\text { Ganho de seleção }\end{array}$ & $\begin{array}{c}13,9,30,41,17,37,21 \\
4,52\end{array}$ & $\begin{array}{c}35,43,63,2,23,52,12 \\
3,24\end{array}$ \\
\hline Willians (1962) & $\begin{array}{c}\text { Famílias selecionadas } \\
\text { Ganho de seleção }\end{array}$ & $\begin{array}{c}13,9,41,30,17,37,43 \\
4,63\end{array}$ & $\begin{array}{c}63,21,35,23,2,1,44 \\
3,15\end{array}$ \\
\hline Pesek \& Baker (1969) e Elston (1963) & $\begin{array}{c}\text { Famílias selecionadas } \\
\text { Ganho de seleção }\end{array}$ & $\begin{array}{c}13,9,30,41,17,37,21 \\
4,60\end{array}$ & $\begin{array}{c}35,43,63,2,23,52,1 \\
3,18\end{array}$ \\
\hline \multicolumn{4}{|c|}{ Amplitude dos valores de médias de famílias } \\
\hline \multicolumn{2}{|l|}{ Menores valores das médias (\%) } & 74,50 & 99,00 \\
\hline \multicolumn{2}{|l|}{ Maiores valores das médias (\%) } & 80,00 & 99,00 \\
\hline \multicolumn{2}{|c|}{ Correlação genética entre vigor e germinação } & & 0,82 \\
\hline \multicolumn{4}{|c|}{ Porcentagem de coincidência de famílias selecionadas } \\
\hline \multicolumn{2}{|l|}{ Direta: vigor x germinação } & & $78,57 \%$ \\
\hline \multicolumn{2}{|c|}{ Direta de vigor e germinação x Smith (1936) e Hazel (1943) } & & $89,01 \%$ \\
\hline \multicolumn{2}{|c|}{ Direta de vigor e germinação x Willians (1962) } & & $89,28 \%$ \\
\hline \multicolumn{2}{|c|}{ Direta de vigor e germinação x Pesek \& Baker (1969) } & & $92,86 \%$ \\
\hline \multicolumn{2}{|c|}{ Direta de vigor e germinação x Elston (1963) } & & $92,86 \%$ \\
\hline
\end{tabular}


A $35{ }^{\circ} \mathrm{C}$, os ganhos estimados pela seleção foram superiores aos aferidos a $20^{\circ} \mathrm{C}$, estando acima de $30 \%$ para os dois caracteres. Todos os índices de seleção tiveram desempenho idêntico com o mesmo ganho estimado e as mesmas famílias selecionadas, indicando que também para essa temperatura qualquer um dos índices de seleção testados poderia ser empregado. A correlação genética entre vigor e germinação a $35^{\circ} \mathrm{C}$ também foi elevada $(0,95)$, assim como o número de famílias idênticas selecionadas pela seleção direta para ambos os caracteres e também a semelhança entre o número de famílias selecionadas diretamente para cada caráter e pelos índices de seleção (Tabela 4).

Pode-se verificar ainda que foi baixa a porcentagem de coincidência de famílias selecionadas para as duas temperaturas em ambos os caracteres, sendo apenas $21,43 \%$ das famílias igualmente selecionadas para cada caráter nas diferentes condições de temperatura, indicando que possivelmente são conjuntos diferentes de genes que são ativados para responder à germinação nas duas temperaturas. Dessa forma, a seleção para germinação em temperaturas elevadas teria que ser efetuada em conjunto com a seleção em temperaturas mais baixas, para evitar a perda da adaptação para germinação em temperaturas mais amenas (Tabela 4).

Pode-se verificar que as avaliações a $20^{\circ} \mathrm{C}$, apesar de propiciar maior precisão das inferências, proporcionou a possibilidade de ganho reduzido por seleção, pois a maioria das famílias teve porcentagens de germinação e vigor de sementes elevadas e com valores semelhantes. A $35^{\circ} \mathrm{C}$, apesar de herdabilidade inferior, os ganhos poderiam ser maiores, pois essa temperatura possibilitou maior separação das famílias quanto aos caracteres testados, porém a precisão experimental foi reduzida. Portanto, adequações na metodologia devem ser testadas, objetivando melhorar a precisão experimental em temperatura de $35^{\circ} \mathrm{C}$, ou seja, reduzir o coeficiente de variação ambiental.

Tabela 4. Estimativas de ganho genético esperado em porcentagem em relação à média, identificação das famílias selecionadas por método de seleção empregado, de acordo com seleção direta e baseado em índices de seleção, percentual de coincidência de famílias selecionadas pelos diferentes métodos, amplitude das médias para os caracteres vigor e germinação de sementes avaliados em condições de laboratório a $35^{\circ} \mathrm{C}$ e correlação genética entre os caracteres.

\begin{tabular}{lccc}
\hline Métodos de seleção & Vigor & Germinação \\
\hline Seleção direta & Famílias selecionadas & $22,58,14,68,10,39,65$, & $21,22,65,14,35,10,58$, \\
& Ganho de seleção & 24, 35, 20, 21, 2, 55, 40 & 68, 70, 2, 24, 69, 20, 39 \\
& Famílias selecionadas & 22, 21, 58, 14, 65, 68, 10, 35, 24, 39, 2, 20, 70, 40 & 30,23 \\
\hline Indices de seleção $^{1}$ & Ganho de seleção & 34,27 & 22,50 \\
& Amplitude dos valores de médias de famílias & 38,00 \\
\hline Menores valores das médias (\%) & & 0,00 & 0,95 \\
Maiores valores das médias (\%) & & 0,00 & \\
Correlação genética entre vigor e germinação & & \\
\hline
\end{tabular}

\section{Porcentagem de coincidência de famílias selecionadas}

\begin{tabular}{ll}
\hline Direta: vigor x germinação & $85,71 \%$ \\
Direta de vigor e germinação x Índices de seleção & $92,86 \%$ \\
Vigor $20^{\circ} \mathrm{C}$ x Vigor $35^{\circ} \mathrm{C}$ & $21,43 \%$ \\
Germinação $20^{\circ} \mathrm{C}$ x Germinação $35^{\circ} \mathrm{C}$ & $21,43 \%$ \\
\hline
\end{tabular}

${ }^{1}$ Smith (1936) e Hazel (1943), Willians (1962), Pesek \& Baker (1969) e Elston (1963). Obs: Nesta temperatura, para ambos os índices avaliados, os ganhos por seleção e as famílias selecionadas foram os mesmos.

\section{CONCLUSÕES}

O vigor e a germinação das sementes foram eficientes para diferenciar as famílias avaliadas a 20 e $35^{\circ} \mathrm{C}$.

Os índices de seleção avaliados tiveram desempenho idêntico nas duas temperaturas testadas, sendo assim a seleção pode ser feita com a utilização de qualquer um dos índices.

A temperatura de $35^{\circ} \mathrm{C}$ mostrou elevado ganho por seleção em relação à de $20^{\circ} \mathrm{C}$.

\section{REFERÊNCIAS}

Alves JC da S, Peixoto JR, Vieira JV \& Boiteux LS (2004) Estimativas de parâmetros genéticos para um conjunto de caracteres de raiz e folhagem em populações de cenoura derivadas da cultivar Brasília. In: 44 Congresso Brasileiro de Olericultura, Brasilia. Horticultura Brasileira, Brasília, 22:475.

Bittencourt MLC (1991) Qualidade de sementes e avaliação das progênies de meio-irmãos de cenoura (Daucus carota L.) "Brasília”. Tese de Mestrado. Universidade Federal de Viçosa, Viçosa. 77p.

Brasil, Ministério da Agricultura (1992) Regras para análise de sementes. Brasília, LANARV/MA. 365p. 
Carneiro JVP \& Guedes TA (1992) Influência da temperatura no desempenho germinativo de sementes de cenoura (Daucus carota L.), avaliada pela função de distribuição de Weibull. Revista Brasileira de Sementes, 14:207-213.

Carvalho FIF de, Silva AS, Kurek AJ \& Marchioro VS (2001) Estimativas e implicações da herdabilidade como estratégia de seleção. Universitária da UFPel. Pelotas. 99p.

Cruz CD (1997) Programa Genes: aplicativo computacional em genética e estatística. Editora UFV, Viçosa. 442p.

Cruz CD \& Regazzi AJ (2001) Modelos biométricos aplicados ao melhoramento genético. Editora UFV, Viçosa. 390p.

Eberhart AS (1970) Factors affecting efficiencies of breeding methods. African Soils, 15:669-680.

Elston RCA (1963) Weight-free index for the purpose of ranking or selection with respect to several traits at a time. Biometrics, 19:85-97.

Hazel LN (1943) The genetic basics for constructing selections indexes. Genetics, 28:476-490.
Pereira RS (2005) Germinação de sementes de cenoura (Daucus carota L.) sob condições de altas temperaturas. Tese de mestrado. Universidade de Brasília, Brasília. 65p.

Pereira RS \& Nascimento WM (2002) Utilização do condicionamento osmótico de sementes de cenoura visando à germinação em condições de temperaturas altas. Horticultura Brasileira, 20:303. Suplemento CD-ROM

Pesek J \& Baker RJ (1969) Desired improvement in relation to selected indices. Canadian Journal Plant Science, 49:803-804.

Santos CAF \& Araújo FP de (2001) Aplicação de índices para seleção de caracteres agronômicos de feijão-de-corda. Ciência Agronômica, 32:1-2.

Smith HF (1936) A discriminant function for plant selection. Annual Symposium of the Eugenics Society, 7:240-250.

Willians JS (1962) The evaluation of a selection index. Biometrics, 18:375-393. 